\title{
Shallow groundwater effect on land surface temperature and surface energy balance under bare soil conditions: modeling and description
}

\author{
F. Alkhaier ${ }^{1}$, G. N. Flerchinger ${ }^{2}$, and Z. Su ${ }^{1}$ \\ ${ }^{1}$ Department of water resources, Faculty of Geo-Information Science and Earth Observation, \\ University of Twente, Enschede, The Netherlands \\ ${ }^{2}$ Northwest Watershed Research Center, United States Department of Agriculture, Washington, D.C., USA \\ Correspondence to: F. Alkhaier (khaier@itc.nl)
}

Received: 7 September 2011 - Published in Hydrol. Earth Syst. Sci. Discuss.: 23 September 2011

Revised: 26 March 2012 - Accepted: 1 May 2012 - Published: 3 July 2012

\begin{abstract}
Understanding when and how groundwater affects surface temperature and energy fluxes is significant for utilizing remote sensing in groundwater studies and for integrating aquifers within land surface models. To investigate the shallow groundwater effect under bare soil conditions, we numerically exposed two soil profiles to identical metrological forcing. One of the profiles had shallow groundwater. The different responses that the two profiles manifested were inspected regarding soil moisture, temperature and energy balance at the land surface. The findings showed that the two profiles differed in three aspects: the absorbed and emitted amounts of energy, the portioning out of the available energy and the heat fluency in the soil. We concluded that due to their lower albedo, shallow groundwater areas reflect less shortwave radiation and consequently get a higher magnitude of net radiation. When potential evaporation demand is sufficiently high, a large portion of the energy received by these areas is consumed for evaporation. This increases the latent heat flux and reduces the energy that could have heated the soil. Consequently, lower magnitudes of both sensible and ground heat fluxes are caused to occur. The higher soil thermal conductivity in shallow groundwater areas facilitates heat transfer between the top soil and the subsurface, i.e. soil subsurface is more thermally connected to the atmosphere. For the reliability of remote sensors in detecting shallow groundwater effect, it was concluded that this effect can be sufficiently clear to be detected if at least one of
\end{abstract}

the following conditions occurs: high potential evaporation and high contrast between day and night temperatures. Under these conditions, most day and night hours are suitable for shallow groundwater depth detection.

\section{Introduction}

Investigating the effect of shallow groundwater on land surface temperature and surface energy balance has two advantages. Firstly, it secures a solid ground for utilizing the thermal remote sensing optimally when observing the areal extent of shallow groundwater and it can also contribute to the developing of future satellite designs. Secondly, in the fields of climate research, weather forecast, and water management studies, this investigation can add to establishing the basis where this effect can be included

The effect of groundwater on soil temperature was noted as early as the 1930's (van den Bouwhuysen, 1934). In one of the pioneering investigations, Kappelmeyer (1957) successfully used near surface soil temperatures $(1.5 \mathrm{~m}$ depth) to locate fissures carrying hot water. Since then, studies have been using soil temperature at shallow depths $(0.5$ to $2 \mathrm{~m})$ to locate aquifers and delineate their flow systems.

Cartwright (1968) made use of temperature measurement at a depth of $0.5 \mathrm{~m}$ to find thermal anomalies caused by shallow aquifers located at a depth of about $5 \mathrm{~m}$. He used a simple 
model to describe heat transport between soil-air interface and aquifer-overburden interface. Though his model was the earliest to describe this process, it included a major shortcoming: both land surface and groundwater had predefined standing temperatures (Dirichlet boundary condition). Obviously, this prevented any thermal interaction between the aquifer and the land surface.

Birman (1969) attributed the small amplitude of the annual shallow-earth temperature wave to the presence of shallow groundwater. A year later, Krcmar and Masin (1970) reported that the most important results of geothermic measurements had been the investigation for circulation of both cold and hot underground waters.

Studies of geothermal prospecting for groundwater were continued by Cartwright $(1971,1974)$. Specifically Cartwright (1974) studied the use of soil temperature measured at $1 \mathrm{~m}$ depth to describe the flow of small, shallow groundwater systems. Afterwards, following the same track, several studies (Takeuchi, 1980, 1981, 1996; Yuhara, 1998 cited in Furuya et al., 2006; Olmsted et al., 1986; Bense and Kooi, 2004; Alkhaier et al., 2009) used thermal prospecting to locate shallow aquifers and to delineate their flow systems.

By the advent of remote sensing technologies, scientists were motivated by the accomplishments that had been realized by the in-situ measurements to employ thermal remote sensing in locating and delineating shallow groundwater systems. The new tool (i.e. remote sensors) provided radiant temperatures of extensive areas.

The majority of investigations that used remote sensing for detecting shallow groundwater effect on surface temperature was conducted between the late 1960's (Chase, 1969) and the early 1980's (Heilman and Moore, 1982). These studies were accompanied with relevant in-situ measurements and modeling efforts; Quiel (1975) measured the radiant temperature of gravel with varying depth of the groundwater table. He concluded that the influence of groundwater on surface temperature was insignificant if it is deeper than $0.2 \mathrm{~m}$ (diurnal damping depth of dry gravel). His conclusion is striking but understandable because gravel allows for a very small capillary rise; consequently, it does not affect the moisture state and the thermal properties of the section above the water table. Furthermore, Quiel's study considered only the penetration of the daily temperature variation and totally neglected the yearly temperature oscillation.

The latter was also neglected in the numerical model built by Huntley (1978), who conducted an important theoretical and practical investigation for aquifer detection using remote sensing. The diurnal numerical model he developed was simple (numerical faculties were not as advanced as it is today), but it was the last and the most detailed model that dealt with this phenomenon. His study concluded that it is impractical to estimate groundwater depth directly using thermal infrared imagery.
Actually, Huntley's investigation underestimated the effect of groundwater on surface temperature mainly because of two reasons. Firstly, his study neither distinguished hot from cold groundwater nor very deep from shallow groundwater. For that reason, the measured subsurface soil temperatures and the depths of groundwater brought forth poor correlation. Secondly, his model was not advanced enough to simulate the inter-connection among energy balance components at the land surface. Moreover, it did not consider the effect of groundwater on soil moisture and thus the thermal properties of the vadose zone.

Recently, there have been keen attempts to include groundwater systems in land surface models (i.e. models that simulate the interactions between soil, vegetation and the atmosphere). York et al. (2002), the earliest to include aquifers within coupled land surface models, triggered a series of investigations that approached the coupling between groundwater and land surface models using different schemes and techniques (Liang and Xie, 2003; Chen and $\mathrm{Hu}, 2004$; Maxwell and Miller, 2005; Gulden et al., 2007; Fan et al., 2007; Niu et al., 2007; Jiang et al., 2009). Careful inspection of these works shows that their focal point was the mass aspect of the linkage between the surface and the subsurface domains via moisture flux. In this way, the main interest was the influence of groundwater, as an extra source of water for evaporation, on water budget at land surface. Specifically, Niu et al. (2007) developed a simple groundwater model (SIMGM) which considers unsaturated soil water and evaluated the model against the Gravity Recovery and Climate Experiment (GRACE) terrestrial water storage change data. Therefore, these studies could not provide a complete prospective of shallow groundwater effect. The temporal patterns of that effect on surface temperature, net radiation, and surface heat fluxes (latent, sensible and ground heat fluxes) have not been featured. More importantly, utilizing thermal remote sensing in these efforts or reversely, utilizing their findings in detecting shallow groundwater via thermal remote sensing has been beyond the scope of these studies.

Prior to any real success in the application of remote sensing techniques in shallow groundwater studies, and prior to solid integration of aquifers within coupled land surface models, it is essential to appreciate the basic physical principles involved in the process. In fact, the question whether shallow groundwater affects land surface temperature or not is still put forth. Furthermore, questions as when and how this effect takes place or whether it is possible to utilize currently operational satellites for its detection have not been adequately answered yet.

In this paper we tackle the aforementioned questions by implementing numerical simulations that take into consideration the majority of the aspects through which shallow groundwater affects land surface temperature and the various components of surface energy balance. In a companion paper (Alkhaier et al., 2012), we support the findings and conclusions of this paper by further investigating the possibility of 
utilizing remotely sensed temperatures as a practical application in featuring this effect.

With respect to the numerical simulation implemented in this study, we expose two soil profiles - one having shallow groundwater - to an identical meteorological forcing. We then look closely at the different responses of both profiles with regards to soil moisture, temperature and energy balance components at the land surface. To investigate how the shallow groundwater effect varies among different soil textures, a set of additional SHAW simulations were performed for three soil textures: sand, loam and clay. For each soil type, simulations were run for a profile with no groundwater (NOGWP) and for profiles with water table at 1, 2, 3, 4, 5 and $10 \mathrm{~m}$ deep. After that, we inspected the differences in soil surface temperature of the different profiles for each soil type. Hereinafter, we outline the general features of shallow groundwater effect. Afterwards, we describe the numerical modeling experiments that had been implemented to depict the expected pattern and magnitude of this effect.

\section{Theory}

Generally speaking, groundwater is defined as the water under positive pressure in the saturated zone of earth materials (Dingman, 2002). Within the context of this paper, "shallow" groundwater means that the water table is close enough to influence soil moisture at the land surface. In such systems, water can move upward from the water table into the vadose zone, driven by surface tension forces. This results in a saturated to nearly-saturated zone of negative pressure above the water table (i.e. capillary fringe or tension-saturated zone) which may range in height from about $10 \mathrm{~mm}$ for gravel, to $1.5 \mathrm{~m}$ for silt and even to several meters for clay (Dingman, 2002). The effect of shallow groundwater on soil moisture in the vadose zone may further extend above the capillary fringe up to the land surface due to two factors. The first is the surface-tension forces. The second is the effect of shallow groundwater on the infiltration rate as a result of air compression and counterflow in bounded soil columns (Grismer et al., 1994; Salvucci and Entekhabi, 1995).

At the land surface, energy fluxes interact instantaneously with each other in accordance with the prevailing meteorological conditions and the specific thermal and radiative characteristics of the soil surface. The surface temperature represents the state variable that continuously adjusts to changes in hydraulic and meteorological forcing in such a way that the energy balance (Eq. 1) is always being preserved:

$R_{\mathrm{n}}=\mathrm{LE}+H+G$.

LE $\left(\mathrm{W} \mathrm{m}^{-2}\right)$ is the latent heat flux that is used for evaporation (in this study we consider bare soil conditions). $H$ $\left(\mathrm{W} \mathrm{m}^{-2}\right)$ is the sensible heat flux which expresses the heat exchange between the land surface and the air above it; $G\left(\mathrm{~W} \mathrm{~m}^{-2}\right)$ is the ground heat flux, that is the heat which transfers downward into the ground or upward to the surface. $R_{\mathrm{n}}\left(\mathrm{W} \mathrm{m}^{-2}\right)$ is the net radiation which is the outcome of the radiation emitted by the sun $\left(K_{\text {in }}\right)$ and the sky $\left(\varepsilon L_{\text {in }}\right)$ onto the land surface, minus the radiation which is reflected $\left(\alpha K_{\text {in }}\right)$ or emitted by the land surface $\left(L_{\mathrm{out}}=\varepsilon \sigma T_{\mathrm{s}}^{4}\right)$, as:

$R_{\mathrm{n}}=(1-\alpha) K_{\text {in }}+\varepsilon L_{\text {in }}-L_{\text {out }}$

where $\alpha, \varepsilon$ are land surface albedo and emissivity respectively. $T_{\mathrm{S}}$ is land surface temperature $(\mathrm{K})$ and $\sigma$ is Stefan-Boltzmann constant $\left(5.6697 \times 10^{-8}\right)$. Soil albedo, $\alpha$, changes according to soil moisture, $\theta_{1}$, as (Idso et al., 1975):

$\alpha=\alpha_{\mathrm{d}} \exp \left[-a_{\alpha} \theta_{1}\right]$

where $\alpha_{\mathrm{d}}$ is dry soil albedo and $a_{\alpha}$ is an empirical coefficient.

Figure 1 presents a sketch of how shallow groundwater affects the different components of the energy balance at the land surface. The component that prospers most when the soil moisture rises due to the presence of shallow groundwater is the latent heat flux (LE). Thus, more energy is consumed for evaporation leaving less energy to heat the soil surface. Consequently, the cooler soil surface induces smaller thermal exchanges between the top surface soil and both the air above (sensible heat flux, $H$ ) and the subsurface soil beneath (ground heat flux, $G$ ).

Furthermore, the presence of shallow groundwater affects thermal properties of both saturated and unsaturated zones. Through its effect on thermal conductivity and volumetric heat capacity of the soil profile, shallow groundwater alters the propagation of heat in the subsurface and thereby affects soil temperature and ground heat flux. While the change in thermal conductivity affects the intensity of ground heat flux and the depths of both diurnal and annual heat penetration, the change in volumetric heat capacity alters the amount of heat that can be preserved in the soil layers. As a result, both the amplitude and the phase of diurnal and annual waves of ground heat flux and soil temperature are affected consequently.

Net radiation, $R_{\mathrm{n}}$, (Eq. 2) has three components that are likely to be influenced by the wetness of land surface, namely; the reflected shortwave radiation $\left(\alpha K_{\text {in }}\right)$ and both absorbed and emitted longwave radiations ( $\varepsilon L_{\text {in }}$ and $\varepsilon \sigma T_{\mathrm{s}}^{4}$ ). The first component $\left(\alpha K_{\text {in }}\right)$ is subject to albedo, while the last two are influenced by emissivity; both albedo and emissivity vary in relation to soil moisture. Nevertheless, soil emissivity may have a minor effect since it is involved in two components of comparable magnitude acting in opposite directions, i.e. $\varepsilon L_{\text {in }}$ and $L_{\text {out }}$ (Eq. 2). Generally, studies that handled the effect of soil moisture on emissivity are few and agree that emissivity increases when the soil moisture increases (Salisbury and Daria, 1992; Mira et al., 2007). Moreover, it was found (Hulley et al., 2010) that a decrease in emissivity of $10 \%$ will result in a decrease in net longwave radiation of only $7 \mathrm{~W} \mathrm{~m}^{-2}$. 


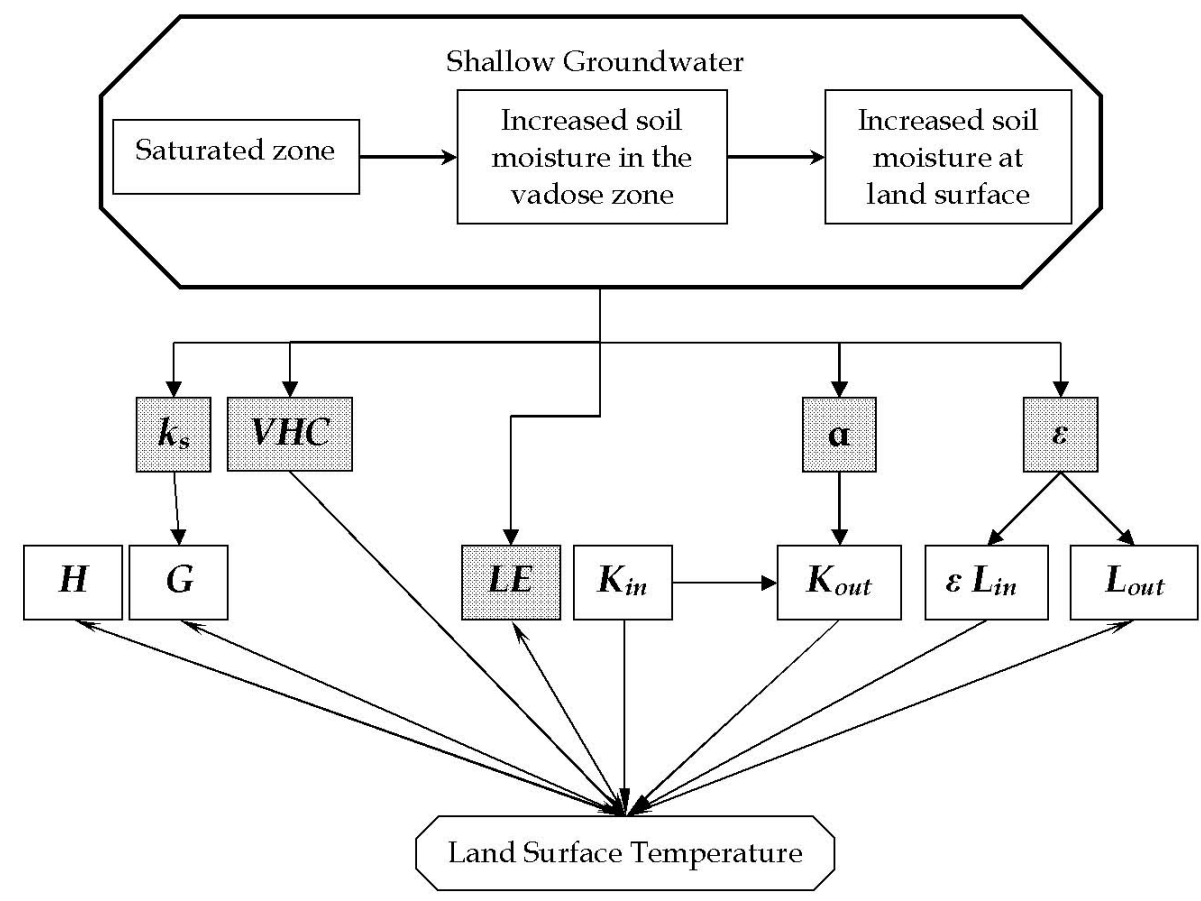

Fig. 1. A schematic description of the effect of shallow groundwater on the land surface temperature and the different components of the surface energy balance.

\section{Methodology}

We used the Simultaneous Heat and Water model (SHAW) (Flerchinger, 2000) to simulate water and heat transfer in the soil and to produce the germane energy fluxes at the land surface. We chose SHAW because it presents the heat and water transfer processes in detailed physics, and has been successfully employed to simulate land surface energy balance over a broad range of conditions and applications (Flerchinger and Cooley, 2000; Flerchinger et al., 2003, 2009; Flerchinger and Hardegree, 2004; Santanello and Friedl, 2003; Huang and Gallichand, 2006).

The simulation was implemented for two different soil profiles that were put under identical forcing meteorological conditions. Though the two profiles were alike in terms of soil composition and profile depth, they differed in one aspect which was the presence of groundwater. One profile had water table perched at $2 \mathrm{~m}$ from land surface (hereafter referred to as the "GWP") whereas the other profile had no groundwater (hereafter designated to as the "NOGWP").

To maintain simplicity, we adopted the following assumptions: (1) both heat and water transfers took place only in the vertical direction (2) the soil was homogeneous in both soil profiles and (3) water table in GWP was stagnant during the simulation period.

Hereinafter, we spotlight the most important expressions adopted in SHAW to obtain surface heat fluxes. And we show how water and heat transfer in the soil profile are mathematically expressed in accordance with Flerchinger (2000).
Afterwards, we describe the experimental design together with the input data (profile depth, soil and weather data, simulation duration and time step).

\subsection{SHAW formulations}

SHAW model simulates a vertical, one-dimensional profile which may extend from the top of possibly existing vegetation canopy, plant residue, snow, or soil surface down to a certain depth within the soil. This system is represented by detailed physics. We present hereinafter some of its fundamental equations that are relevant to our specific simulation purpose. For further details the reader is referred to SHAW technical documentation (Flerchinger, 2000).

\subsubsection{Surface heat fluxes}

Sensible heat flux is related to temperature gradient between the soil surface and the atmosphere. Following Campbell (1977), we write:

$H=\rho_{\mathrm{a}} c_{\mathrm{a}} \frac{\left(T_{\mathrm{s}}-T_{\mathrm{a}}\right)}{r_{\mathrm{H}}}$

where $\rho_{\mathrm{a}}, c_{\mathrm{a}}$, and $T_{\mathrm{a}}$ are air density $\left(\mathrm{kg} \mathrm{m}^{-3}\right)$, specific heat $\left(\mathrm{J} \mathrm{kg}^{-1}{ }^{\circ} \mathrm{C}^{-1}\right)$ and temperature $\left({ }^{\circ} \mathrm{C}\right)$ at the measurement reference height $z_{\text {ref }} ; T_{\mathrm{S}}$ is the temperature $\left({ }^{\circ} \mathrm{C}\right)$ of soil surface, and $r_{\mathrm{H}}$ is the resistance to surface heat transfer $\left(\mathrm{s} \mathrm{m}^{-1}\right)$ corrected for atmospheric stability. 
Latent heat flux is associated with water vapor transfer from soil surface to the atmosphere, as:

$L E=-L \frac{\left(\rho_{\mathrm{vs}}-\rho_{\mathrm{va}}\right)}{r_{\mathrm{v}}}$

where $L$ is the latent heat of vaporization $\left(\mathrm{J} \mathrm{kg}^{-1}\right), E$ is vapor flux $\left(\mathrm{kg} \mathrm{s}^{-1} \mathrm{~m}^{-2}\right), \rho_{\mathrm{vs}}$ and $\rho_{\mathrm{va}}$ are vapor density $\left(\mathrm{kgm}^{-3}\right)$ of soil surface and air at the reference height. The resistance value for vapor transfer $r_{\mathrm{v}}\left(\mathrm{s} \mathrm{m}^{-1}\right)$ is assumed to be equal to the resistance to surface heat transfer $r_{\mathrm{H}}$.

The resistance to surface heat transfer, $r_{\mathrm{H}}$, is calculated from:

$r_{\mathrm{H}}=\frac{1}{u_{*} k}\left[\ln \left(\frac{z_{\text {ref }}-d+z_{\mathrm{H}}}{z_{\mathrm{H}}}\right)+\psi_{\mathrm{H}}\right]$

where $u_{*}$ is the friction velocity $\left(\mathrm{m} \mathrm{s}^{-1}\right)$ :

$u_{*}=u k\left[\ln \left(\frac{z_{\mathrm{ref}}-d+z_{\mathrm{m}}}{z_{\mathrm{m}}}\right)+\psi_{\mathrm{m}}\right]^{-1}$

$u$ is wind speed $\left(\mathrm{m} \mathrm{s}^{-1}\right), k$ is von Karman's constant, $d$ is the zero plane displacement. The surface roughness parameter for momentum transfer, $z_{\mathrm{m}}$, is an input parameter to SHAW and estimated by the user. (Typical value is $0.1 \mathrm{~cm}$ for a very smooth surface to $10 \mathrm{~cm}$ for a very rough surface.) The surface roughness parameter for the temperature profile, $z_{\mathrm{H}}$ is assumed to be $0.2 z_{\mathrm{m}} . \Psi_{\mathrm{m}}$ and $\Psi_{\mathrm{H}}$ are the stability correction functions for momentum and heat transfer respectively. Atmospheric stability is expressed as the ratio of thermally induced to mechanically induced turbulence (Campbell, 1977):

$s=\frac{k z_{\mathrm{ref}} g H}{\rho_{\mathrm{a}} c_{\mathrm{a}}\left(T_{\mathrm{a}}+273.16\right) u_{*}^{3}}$

where $g$ is the gravitational acceleration $\left(\mathrm{m} \mathrm{s}^{-2}\right)$.

When $s>0$ (stable conditions):

$\psi_{\mathrm{H}}=\psi_{\mathrm{m}}=4.7 \mathrm{~s}$

and when $s<0$ (unstable conditions):

$\psi_{\mathrm{m}} \approx 0.6 \psi_{\mathrm{H}}$ and $\psi_{\mathrm{H}}=-2 \ln \left(\frac{1+\sqrt{1-16 s}}{2}\right)$.

Ground heat flux, $G$, is a function of thermal conductivity, $k_{\mathrm{S}}$, and soil temperature gradient, $\partial T / \partial z$, and expressed by:

$G=-k_{\mathrm{s}} \frac{\partial T}{\partial z}$.

Ground heat flux is computed by solving for a surface temperature that satisfies surface energy balance, which is solved iteratively and simultaneously with the equations for heat and water fluxes within the soil profile (Eqs. 12 and 15).

\subsubsection{Heat transfer in the soil matrix}

The governing equation for temperature variation in the soil matrix in SHAW considers, in addition to heat conduction, latent heat of water freezing and ice thawing, convective heat transfer by liquid water flux and latent heat transfer by vapor:

$$
\begin{aligned}
\operatorname{VHC} & \frac{\partial T}{\partial t}-\rho_{\mathrm{i}} L_{\mathrm{f}} \frac{\partial \theta_{\mathrm{i}}}{\partial t} \\
& =\frac{\partial\left(k_{\mathrm{s}} \partial T\right)}{\partial^{2} z}-\mathrm{VHC}_{\mathrm{W}} \frac{\partial q_{\mathrm{l}} T}{\partial z}-L\left(\frac{\partial q_{\mathrm{v}}}{\partial z}+\frac{\partial \rho_{\mathrm{v}}}{\partial t}\right)
\end{aligned}
$$

where $\rho_{\mathrm{i}}$ is ice density $\left(\mathrm{kg} \mathrm{m}^{-3}\right) ; L_{\mathrm{f}}$ is the latent heat of fu$\operatorname{sion}\left(\mathrm{J} \mathrm{kg}^{-1}\right) ; \theta_{\mathrm{i}}$ is the volumetric ice content $\left(\mathrm{m}^{3} \mathrm{~m}^{-3}\right)$; VHC and $\mathrm{VHC}_{\mathrm{W}}$ are the volumetric heat capacity of soil matrix and water respectively $\left(\mathrm{J} \mathrm{m}^{-3}{ }^{\circ} \mathrm{C}^{-1}\right) ; q_{1}$ is the liquid water flux $\left(\mathrm{m} \mathrm{s}^{-1}\right) ; q_{\mathrm{v}}$ is the water vapor flux $\left(\mathrm{kg} \mathrm{m}^{-2} \mathrm{~s}^{-1}\right)$ and $\rho_{\mathrm{v}}$ is the vapor density $\left(\mathrm{kg} \mathrm{m}^{-3}\right)$.

Soil thermal properties are calculated according to de Vries (1963). Hence, the soil thermal conductivity $k_{\mathrm{s}}$ ( $\mathrm{W} \mathrm{m}^{-1}{ }^{\circ} \mathrm{C}^{-1}$ ) is expressed as:

$k_{\mathrm{s}}=\frac{\sum m_{j} k_{j} X_{j}}{\sum m_{j} X_{j}}$

and the soil volumetric heat capacity $\operatorname{VHC}\left(\mathrm{J} \mathrm{m}^{-3}{ }^{\circ} \mathrm{C}^{-1}\right)$ is expressed as:

$\mathrm{VHC}=\sum \mathrm{VHC}_{j} X_{j}$

where $k_{j}, \mathrm{VHC}_{j}, m_{j}$ and $X_{j}$ are the thermal conductivity, the volumetric heat capacity, the weighting factor and volumetric fraction of the $j$-th soil constituent (i.e. sand, silt, clay, organic matter, water, ice and air).

\subsubsection{Water and vapor fluxes in the soil matrix}

The governing equation for water movement within soil matrix is expressed in SHAW by extending the traditional Richards equation to include the dynamic change in volumetric ice content and water vapor flux in the soil pores:

$$
\frac{\partial \theta_{1}}{\partial t}+\frac{\rho_{\mathrm{i}}}{\rho_{1}} \frac{\partial \theta_{\mathrm{i}}}{\partial t}=\frac{\partial}{\partial z}\left[k_{\mathrm{h}}\left(\frac{\partial \Psi}{\partial z}+1\right)\right]+\frac{1}{\rho_{\mathrm{l}}} \frac{\partial q_{\mathrm{v}}}{\partial z}+U
$$

where $\theta_{1}$ is the volumetric liquid water content $\left(\mathrm{m}^{3} \mathrm{~m}^{-3}\right), \rho_{\mathrm{l}}$ is the liquid water density $\left(\mathrm{kg} \mathrm{m}^{-3}\right) ; k_{\mathrm{h}}$ is the unsaturated hydraulic conductivity $\left(\mathrm{m} \mathrm{s}^{-1}\right) ; \Psi$ is the soil matric potential (m) and $U$ is a source/sink term $\left(\mathrm{m}^{3} \mathrm{~m}^{-3} \mathrm{~s}^{-1}\right)$.

The moisture characteristic equation is expressed as (Brooks and Corey, 1966; Campbell, 1974):

$$
\Psi=\Psi_{\mathrm{ae}}\left(\frac{\theta_{\mathrm{l}}}{\phi}\right)^{-b}
$$




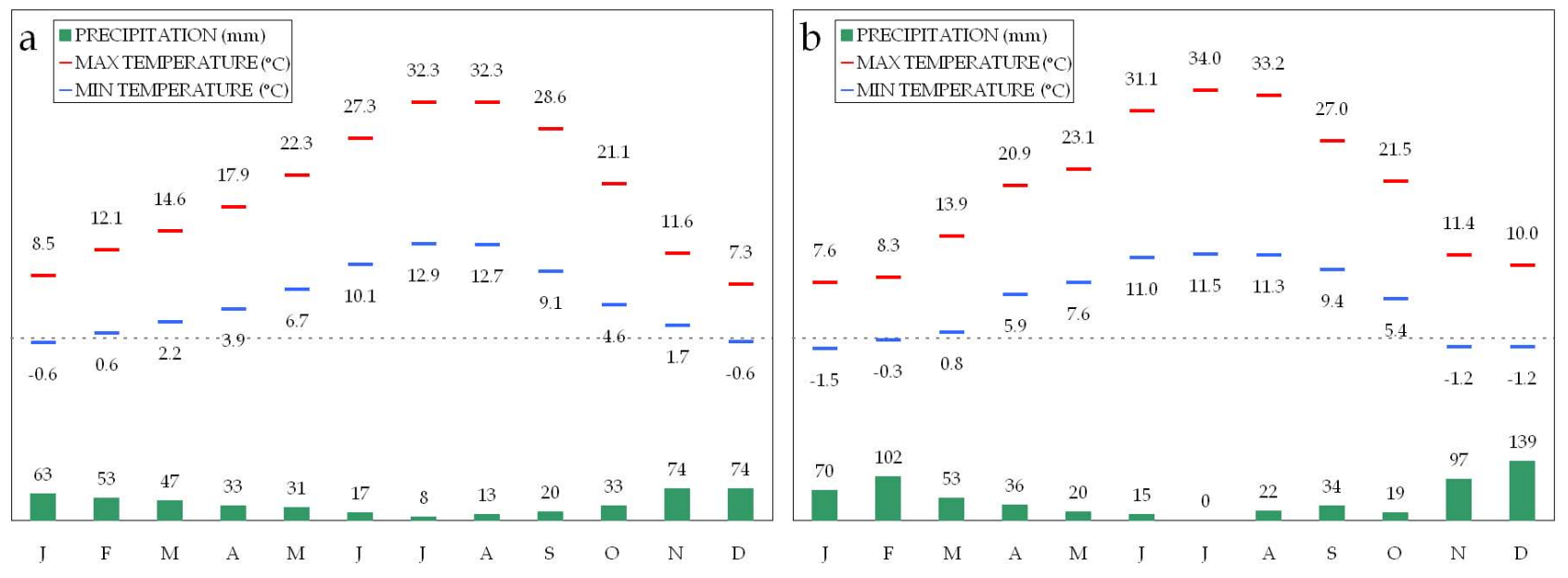

Fig. 2. (a) The climate chart for Medford, Oregon, the USA, and (b) the monthly averaged data for the minimum and the maximum temperatures and the precipitation of the simulated year.

where $\Psi_{\mathrm{ae}}$ is air entry potential (m), $b$ is a pore size distribution parameter, and $\phi$ is soil porosity $\left(\mathrm{m}^{3} \mathrm{~m}^{-3}\right)$. Unsaturated hydraulic conductivity is computed from:

$k_{\mathrm{h}}=k_{\mathrm{h}}^{*}\left(\frac{\theta_{\mathrm{l}}}{\phi}\right)^{2 b+3}$

where $k_{\mathrm{h}}^{*}$ is saturated hydraulic conductivity $\left(\mathrm{m} \mathrm{s}^{-1}\right)$.

Vapor flux in soil pores occurs because of the gradient in vapor density. The latter is the result of both water potential gradient, $q_{\mathrm{vp}}$, and temperature gradient $q_{\mathrm{vT}}$ (Campbell, 1985), so:

$q_{\mathrm{v}}=q_{\mathrm{vp}}+q_{\mathrm{vT}}=-D_{\mathrm{v}} \rho_{\mathrm{v}} \frac{\mathrm{d} h_{\mathrm{r}}}{\mathrm{d} z}-\xi D_{\mathrm{v}} h_{\mathrm{v}} s_{\mathrm{v}} \frac{\mathrm{d} T}{\mathrm{~d} z}$

where $D_{\mathrm{v}}$ is vapor diffusivity within the soil matrix $\left(\mathrm{m}^{2} \mathrm{~s}^{-1}\right)$; $\xi$ is an enhancement factor; $s_{\mathrm{V}}\left(\mathrm{kg} \mathrm{m}^{-3}{ }^{\circ} \mathrm{C}^{-1}\right)$ is the slope of the saturated vapor pressure curve $\left(\mathrm{d} \rho_{\mathrm{v}}^{\prime} / \mathrm{d} T\right)$ and $h_{\mathrm{r}}$ is relative humidity in the soil matrix and given by:

$h_{\mathrm{r}}=\exp \left(\frac{M_{\mathrm{w}} g}{R T_{\mathrm{k}}} \psi\right)$.

Here $M_{\mathrm{w}}$ is the molecular weight of water $\left(\mathrm{kg} \mathrm{mol}^{-1}\right), g$ is gravity acceleration $\left(\mathrm{m} \mathrm{s}^{-2}\right), R$ is the universal gas constant $\left(\mathrm{J} \mathrm{mol}^{-1}{ }^{\circ} \mathrm{C}^{-1}\right)$, and $\psi$ is the water pressure head (m).

The one-dimensional state equations describing energy and water balance are written in an implicit finite difference form and solved using an iterative Newton-Raphson technique for infinitely small layers.

Soil conditions in the soil profile and the atmospheric forcing above the upper boundary (land surface) define heat and water fluxes in the system. Consequently, the input to the SHAW model includes (a) meteorological data and general site information, (b) soil composition and hydraulic parameters and (c) initial soil temperature and moisture.

\subsection{Simulation duration, time step and the applied meteorological data}

All simulations were run for one year duration, after three years of pre-simulation in order to reach proper initial boundary conditions (i.e. soil moisture and temperature profiles). The pre-simulations for both GWP and NOGWP were launched based on the average model states (equilibrium states). The equilibrium states were reached after repeated model runs using the meteorological forcing of the year which characterizes the climatology of the simulated area (Fig. 2a). According to equilibrium states, the temperature at the lower boundary of the soil profile was $15.4^{\circ} \mathrm{C}$ for GWP and $16.6^{\circ} \mathrm{C}$ for NOGWP. The time step was chosen to be $1 \mathrm{~h}$.

The daily weather input data includes minimum and maximum temperatures, dew point, wind speed, precipitation, and total solar radiation. The weather input data in this study was artificially generated by the weather generator model GEM (Generation of weather Elements for Multiple applications, Johnson et al., 1996, 2000) for Medford, Oregon, the USA, which has Mediterranean climate (Köppen climate classification, Kottek et al., 2006; Peel et al., 2007). This climate was chosen because it is a temperate climate and characterized by two distinctive seasons: warm dry summer and cool wet winter. Figure $2 b$ shows monthly averaged data for minimum and maximum temperatures and precipitation of the year under consideration.

\subsection{Soil profile information}

The soil of both profiles was chosen to be loam, which is medium-textured soil and contains a relatively even mixture of sand, silt, and clay (Brown, 2003). The soil texture composition and hydraulic parameters are listed in Table 1 (Clapp and Hornberger, 1978). The depth of both profiles was assigned to be $30 \mathrm{~m}$ to ensure that it is deeper than the common 
Table 1. The texture composition and the physical properties of the soils used in the SHAW simulations.

\begin{tabular}{lllll}
\hline Property & Unit & Sand & Loam & Clay \\
\hline Sand percentage & $\%$ & 90 & 40 & 18 \\
Silt percentage & $\%$ & 7 & 40 & 19 \\
Clay percentage & $\%$ & 3 & 20 & 63 \\
Porosity $\phi$ & - & 0.395 & 0.451 & 0.482 \\
Bulk density $\rho_{\mathrm{b}}$ & $\mathrm{kg} \mathrm{m}^{-3}$ & 1603 & 1455 & 1373 \\
Pore-size distribution index $b$ & - & 4.05 & 5.39 & 11.4 \\
Air-entry potential $\psi_{\mathrm{a} e}$ & $\mathrm{~m}$ & 0.121 & 0.478 & 0.802 \\
Saturated conductivity $k_{\mathrm{h}}^{*}$ & $\mathrm{~m} \mathrm{~s}^{-1}$ & $1.76 \mathrm{E}-4$ & $6.95 \mathrm{E}-6$ & $1.28 \mathrm{E}-6$ \\
Dry soil albedo $\alpha$ & - & 0.3 & 0.2 & 0.2 \\
\hline
\end{tabular}

annual depth of heat penetration. The Vertical node spacing was distributed gradually downwards as the depth increased; it started with $5 \mathrm{~cm}$ over the first $40 \mathrm{~cm}$ and smoothly increased to reach $1 \mathrm{~m}$ at further depths. The lower boundary condition at the bottom of both profiles was set as a fixed temperature (Dirichlet boundary condition) that is equal to the mean annual temperature at the simulated site. Matric potential of the bottom soil layer for the profile with shallow groundwater was set to maintain a water table at $2 \mathrm{~m}$ below the soil surface. The lower boundary for the water flow of the profile with no water table (NOGWP) was assumed to be gravitational flow.

After solving for heat and water fluxes in the soil simultaneously with the energy balance at the soil surface for each profile, the model provided for each time step the parameters of our concern, i.e. soil moisture, soil temperature, net radiation and heat fluxes (latent, sensible and ground heat fluxes) at the land surface. Temperature and moisture of the surface $2.5 \mathrm{~cm}$ soil layer within the model were taken as "surface" conditions. The different responses of both profiles were compared with respect to the abovementioned parameters.

\section{Simulation results and discussion}

At the surface of both NOGWP and GWP, Fig. 3 presents monthly averaged values of (a) soil moisture; (b) soil temperature; (c) net radiation; (d) latent heat flux; (e) sensible heat flux; and (f) ground heat flux, for the simulated year.

Surface soil moisture (Fig. 3a) of GWP persisted at high levels all year round. This was due to the incessant water supply from the shallow water table. This supply was not available for NOGWP which suffered moisture deficit in summer as a result of the increase in potential evaporation and the absence of frequent rainfalls.

Surface soil temperature (Fig. 3b) of GWP was slightly higher than that of NOGWP in winter and noticeably lower in summer. We ascribe the higher surface temperature of GWP in wintertime to its higher volumetric heat capacity. This effect revealed itself despite the counteractive effects of evaporation and longwave radiation emission. While the latent heat flux was exploiting the higher temperature in more
Table 2. The yearly averaged values of the surface soil moisture, the surface soil temperature and the surface energy balance components of the simulated year.

\begin{tabular}{lcrrrrc}
\hline $\begin{array}{l}\text { Variable/ } \\
\text { unit }\end{array}$ & $\begin{array}{c}\theta_{\mathrm{l}} \\
\mathrm{m}^{3} \mathrm{~m}^{-3}\end{array}$ & $\begin{array}{r}T_{\mathrm{S}} \\
{ }^{\circ} \mathrm{C}\end{array}$ & $\begin{array}{r}R_{\mathrm{n}} \\
\mathrm{W} \mathrm{m}^{-2}\end{array}$ & $\begin{array}{c}\mathrm{LE} \\
\mathrm{W} \mathrm{m}^{-2}\end{array}$ & $\begin{array}{c}H \\
\mathrm{~W} \mathrm{~m}^{-2}\end{array}$ & $\begin{array}{c}G \\
\mathrm{~W} \mathrm{~m}^{-2}\end{array}$ \\
\hline NOGWP & 0.18 & 17.1 & 68.70 & 33.44 & 32.74 & 2.52 \\
GWP & 0.34 & 15.2 & 100.42 & 83.52 & 15.67 & 1.24 \\
\hline
\end{tabular}

evaporation, the longwave radiation was continuously alleviating land surface temperature by emitting energy into the atmosphere. Nevertheless, the latter two effects were minor in winter. In summertime, evaporation played a major role in cooling down the soil surface of GWP.

Net radiation (Fig. 3c) of GWP was generally higher than that of NOGWP all through the year. The higher soil moisture of GWP resulted in lower surface albedo (Eq. 3); this, in turn, induced smaller magnitude of reflected shortwave radiation which caused higher net radiation (Eq. 2).

Latent heat flux (Fig. 3d) of GWP was continually higher than that of NOGWP. While GWP had boundless supply of water, NOGWP lacked that supply to meet the demand of potential evaporation. This was especially apparent during the dry hot summer at what time the difference in LE between the two profiles was at its highest level.

Synchronized with soil temperature behavior, sensible heat flux (Fig. 3e) of GWP got a little higher in winter and noticeably lower in summer.

In comparison to NOGWP, ground heat flux of GWP had the propensity to be weaker when it was positive and stronger when it was negative (Fig. 3f). Since soil thermal conductivity, $k_{\mathrm{s}}$, was always higher in GWP, the magnitude of soil temperature gradient, $\partial T / \partial z$, controlled which profile had higher $G$ (Eq. 11). This indicates that NOGWP had higher ground heat flux only when its soil temperature gradient $\partial T / \partial z$ was significantly higher than it was in GWP. This happened mainly during the months when the profile depth was gaining heat, i.e. ground heat flux was downward (positive), and coincided with the months when surface temperature of NOGWP was considerably higher than that of GWP.

The yearly averaged values (Table 2) of the variables shown in Fig. 3, indicates that in the long run, GWP had higher values for soil moisture, net radiation and latent heat flux and lower values for soil temperature, sensible heat flux and ground heat flux.

In GWP, the ample surface soil moisture, which was endowed by the nearby water table, decreased the albedo. This in turn made the net radiation higher. Latent heat flux was also higher due to the abundant soil moisture which facilitated satisfying potential evaporation demand. This demand could not be met in NOGWP, and the extra available energy was consumed for increasing soil temperature. The increased soil surface temperature brought on higher magnitudes of sensible and ground heat fluxes. 


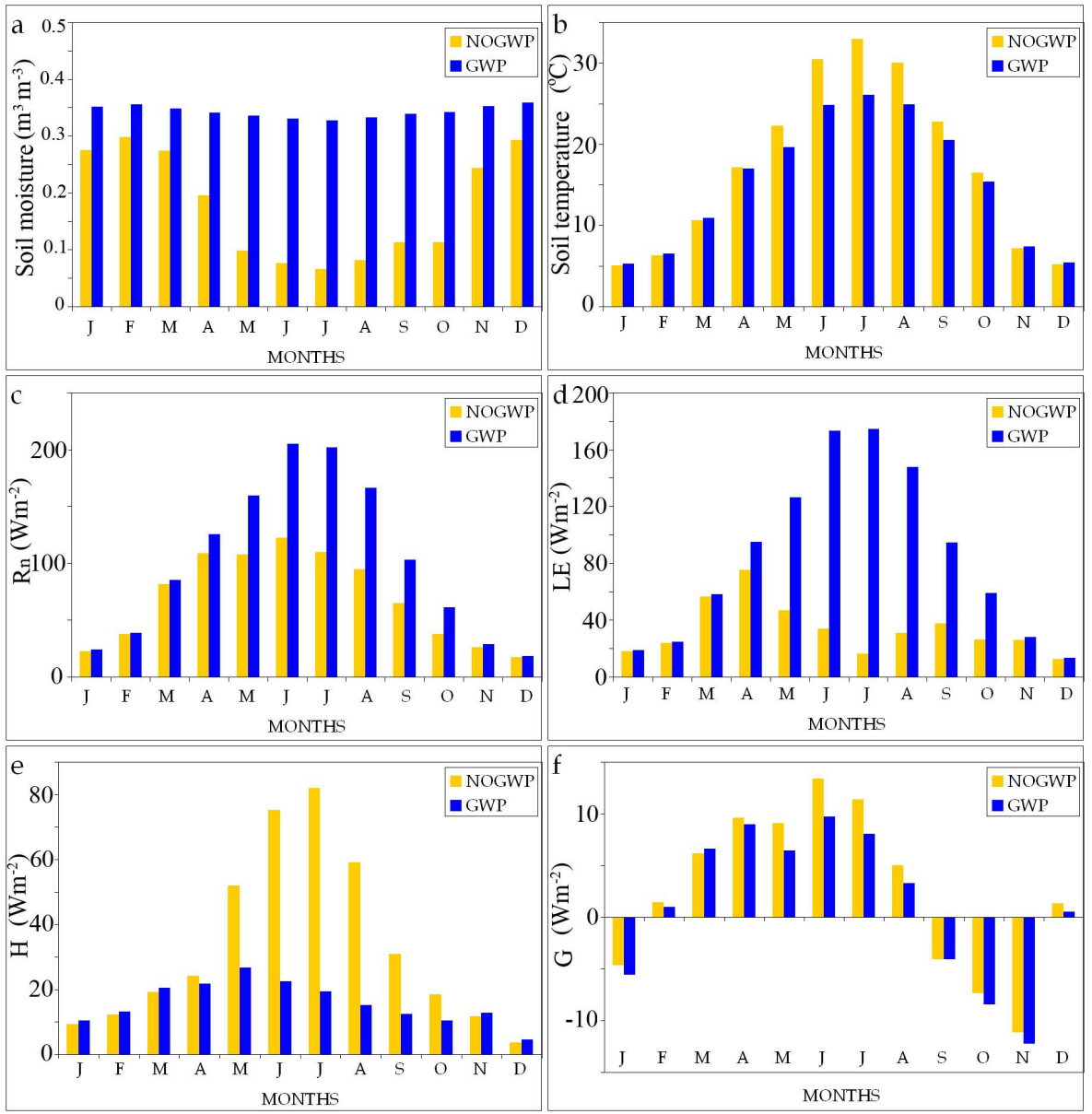

Fig. 3. The monthly averaged values of the surface soil moisture, the surface soil temperature and the surface energy balance components of the simulated year.

In our simulations, GWP had lower ground heat flux, though it had a higher soil thermal conductivity. Thermal conductivity affects heat flux intensity in both vertical directions, thus its effect fades away in the long run. Under this condition, the soil temperature gradient, $\partial T / \partial z$, becomes the sole factor that controls the ground heat flux magnitude (Eq. 11). Given that GWP had milder surface soil temperature fluctuations which induced smaller soil temperature gradients, the yearly upshot of ground heat flux was smaller in GWP. We observe that the annual ground heat flux was positive because this year was a bit warm. So, the subsurface gained heat. In a cold year, however, the subsurface loses heat and the yearly ground heat flux upshot is negative. In the long run, deep soil temperatures eventually come into equilibrium with surface and climate conditions; and are very close to the average annual temperature of the soil surface. As a result, the annual average ground heat flux for both profiles should be very close to zero.

To get a bird's eye view of the instantaneous behavior of the two profiles in terms of the variables under consideration, we zoomed into two-hourly averaged data for three days: one typical winter day (3 January ), one typical summer day (16 July) and one wet summer day (19 June).

In the winter day (Fig. 4), both profiles were comparably wet, though surface soil moisture of GWP was slightly higher (Fig. 4a). This emphasizes that the two profiles react in a different way to rain incidents in terms of their soil moisture. Figure $4 \mathrm{~b}$ shows that the surface temperature of GWP becomes slightly higher than that of NOGWP when the temperature falls, and vice versa. This can be explained by the difference in volumetric heat capacity between the two profiles; wetter soil has higher volumetric heat capacity and needs more time to warm up or cool down. Net radiation of GWP was slightly higher day and night (Fig. 4c). During nighttime, the higher negative net radiation of GWP was caused by the higher outgoing longwave radiation. The effect of the lower albedo of GWP appeared during daytime through a small increment in its positive net radiation. Similarly, ground heat flux of GWP was a little higher most of the time (Fig. 4f). Both latent and sensible heat fluxes of GWP remained somewhat higher day and night except for a few hours after noon (Fig. 4d and e). 


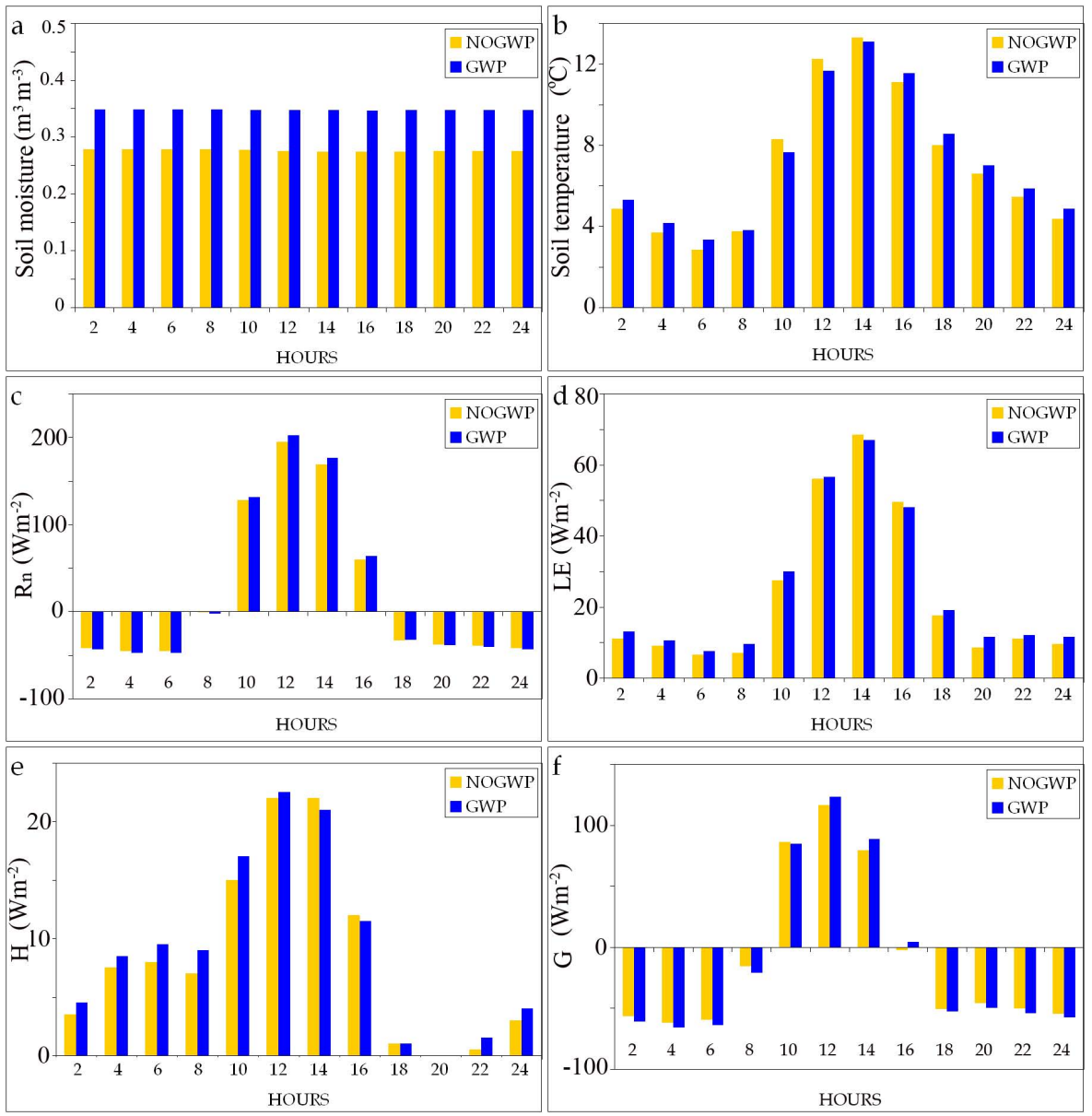

Fig. 4. The surface soil moisture, the surface soil temperature and the surface energy balance components of the two profiles on a winter day (3 January of the simulated year).

In this winter day, the low atmospheric demand for moisture (i.e. potential evaporation), the low temperature contrast between day and night and the comparable wetness status of the two profiles made the differences between them slight in terms of the discussed parameters. On the contrary, the summer day demonstrated large and clear differences (Fig. 5).

The high potential evaporation rapidly consumed the available soil moisture in both profiles (Fig. 5a). However, the deficit in soil moisture of GWP was compensated by upward fluxes of both water and vapor from the water table. This resulted in a considerably higher soil moisture and latent heat flux in this profile (Fig. 5a and d). Land surface temperature and hence sensible heat flux of GWP were remarkably lower both day and night (Fig. $5 b$ and e). The absolute value of the net radiation for GWP was higher during daytime, but a little lower in nighttime (Fig. 5c). Finally, ground heat flux of GWP tended to be stronger than that of NOGWP most of the time (Fig. 5f). The higher thermal conductivity of GWP induced clearly stronger ground heat flux during nighttime. During daytime, the higher surface temperature of NOGWP imposed higher soil temperature gradient, $\partial T / \partial z$, and resulted in comparable ground heat flux values between the two profiles.

It is worth mentioning here what happened after it had rained in summer (Fig. 6). The rain temporarily compensated the moisture deficit in NOGWP, thus the change occurred chiefly in this profile. The differences between the two profiles became smaller regarding land surface temperature, net radiation, latent heat and sensible heat fluxes. This recalls the situation of the winter day (Fig. 4), but with more pronounced differences, e.g. difference of more than $\pm 1.5^{\circ} \mathrm{C}$ in land surface temperature. The increased surface soil moisture of NOGWP after the rainfall (Fig. 6a compared to Fig. 5a) increased the latent heat flux (Fig. 6d) and decreased the surface albedo which caused the increment in daytime net radiation (Fig. 6c). The surface soil temperature of NOGWP dropped and became comparable to that of GWP (Fig. 6b). Here, we notice that the effect of the difference in volumetric heat capacity became clear again, particularly when surface temperature of GWP dropped more slowly during the decreasing phase. Harmonized with the surface soil temperature, the sensible heat flux of NOGWP decreased to the 


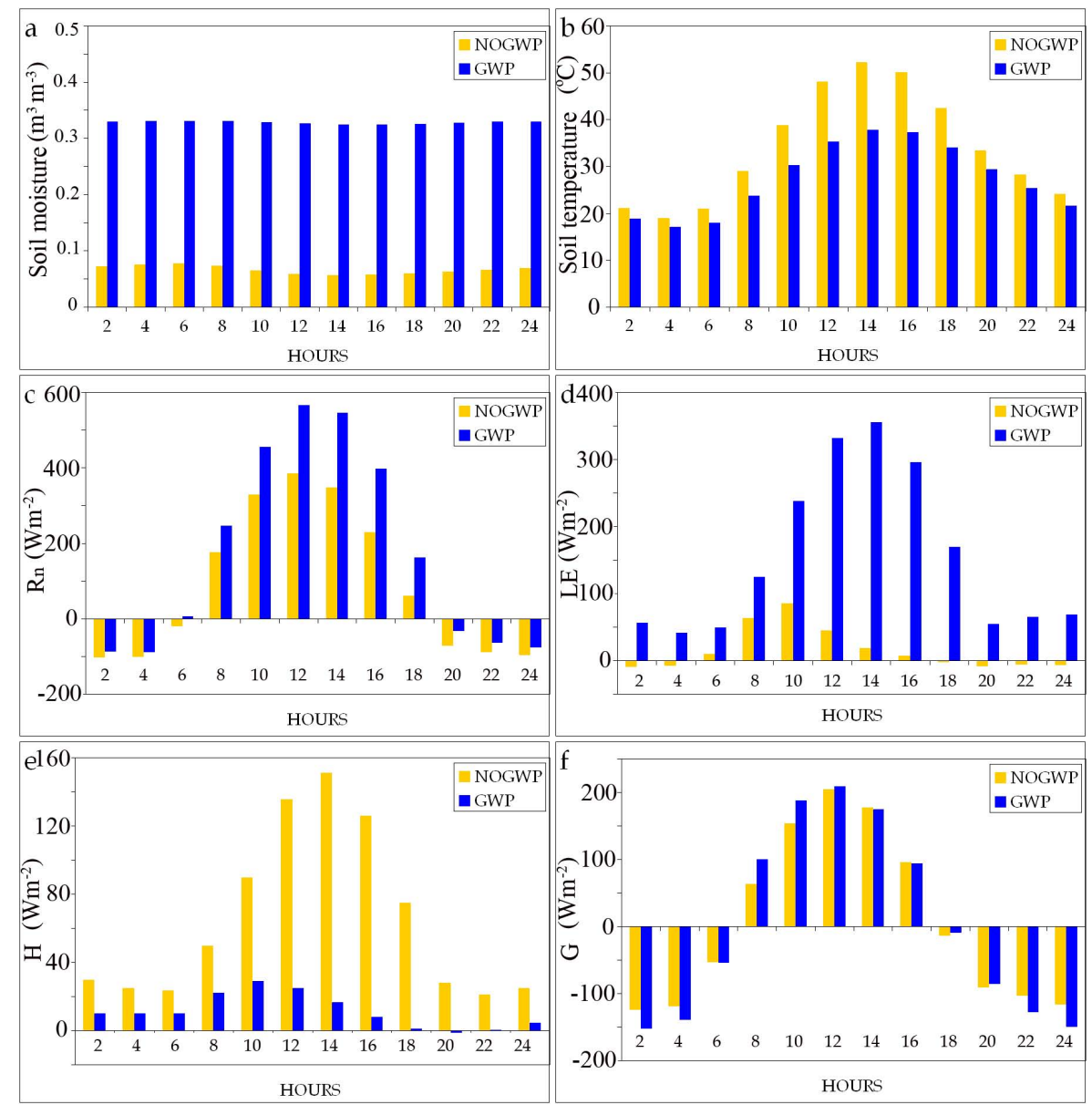

Fig. 5. The surface soil moisture, the surface soil temperature and the surface energy balance components of the two profiles on a summer day (16 July of the simulated year).

extent it became comparable to that of GWP (Fig. 6e). Finally, the ground heat flux of NOGWP decreased during daytime (downward flux), because of the cooling surface temperature which decreased the soil temperature gradient, $\partial T / \partial z$ (Fig. 6f).

The above results show that GWP is more capable of meeting the demand of potential evaporation. When evaporation is not that intense or precipitation provides both profiles with adequate amount of moisture, differences in latent heat flux are minor between the two profiles. Under such conditions, the latent heat fluxes of the two profiles have approximately the same values.

On the other hand, latent heat flux plays a major role in differentiating between the two profiles when potential evaporation is sufficiently strong. Thus, large portion of the available energy for GWP is consumed by evaporation, leaving less energy to warm the soil surface. Consequently, the cooler soil surface causes smaller exchange of heat with the air above the land surface (i.e. sensible heat flux) and with the subsurface soil layers (i.e. ground heat flux).
Nevertheless, the increment of latent heat flux due to the excess of soil moisture is not the sole player within the course of shallow groundwater effect on surface temperature and surface energy balance. Actually, the results show that there are other factors that play a role in shaping and molding this effect. Because of its higher moisture, GWP has different values of volumetric heat capacity, thermal conductivity, albedo and emissivity (Fig. 1). Accordingly, the two profiles differ in the absorbed and emitted amounts of energy, and also in heat fluency in the soil. In other words, both profiles respond differently to the atmospheric forcing.

The effect of volumetric heat capacity was clear in the temperature behavior when the difference in wetness between the two profiles was not severe, i.e. in the winter day and the rainy summer day (Figs. 4 and 6). Under this condition, the profile with higher volumetric heat capacity (GWP) showed a delayed temperature response during both increasing and decreasing phases. And, the effect of thermal conductivity was clear in the increase of the intensity of ground heat flux in GWP while the effect of albedo was clear in the increment of its net radiation. Finally, the effect of emissivity as 


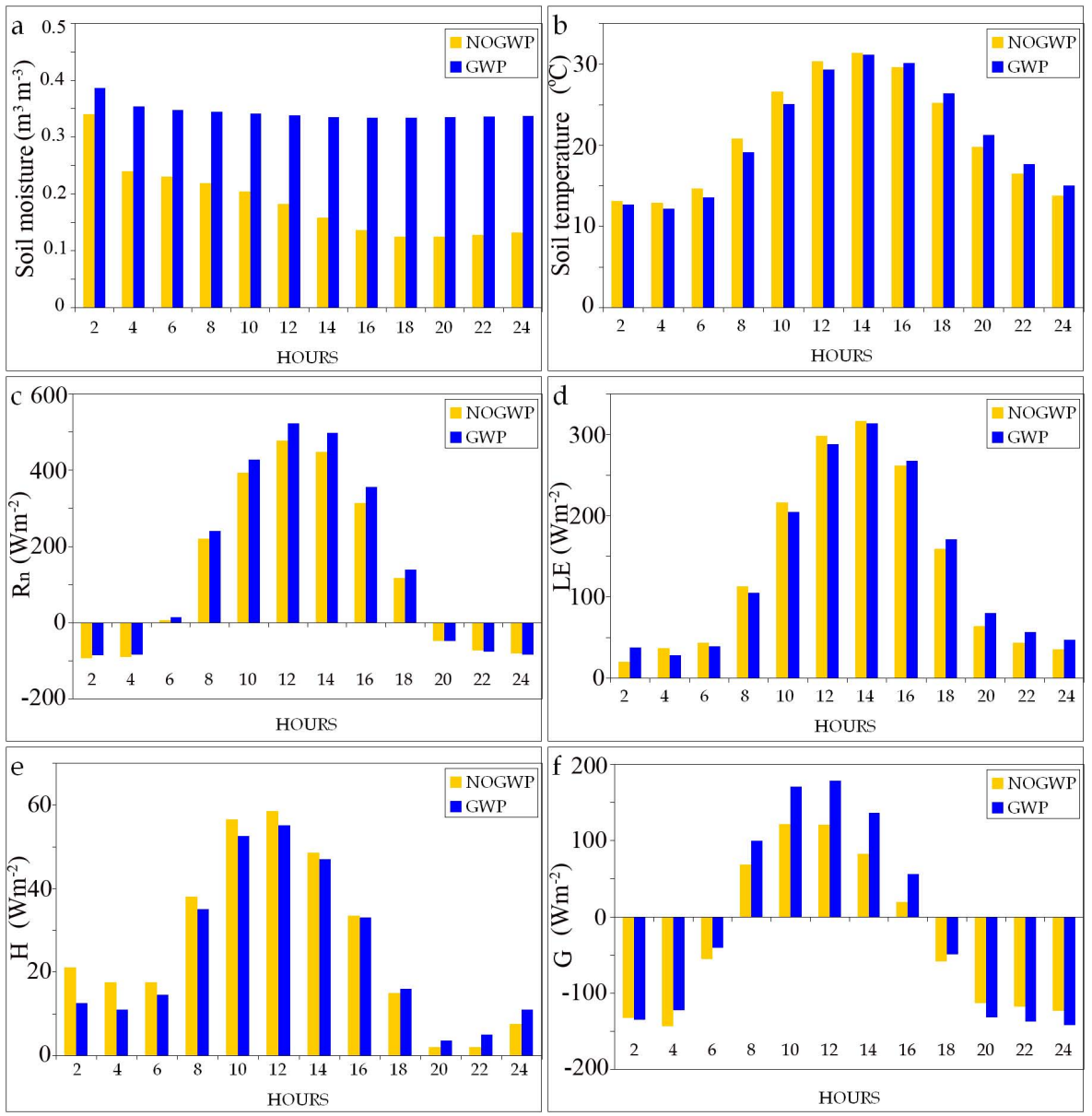

Fig. 6. The surface soil moisture, the surface soil temperature and the surface energy balance components of the two profiles on a wet summer day (19 June of the simulated year).

aforementioned is minor due to its two fold connection to both incoming and outgoing longwave radiations. These two radiations have generally comparable magnitudes and act in opposite directions. Actually, we cannot trace this effect in the figures presented in this study because SHAW adopts a constant value of emissivity of 1.0 and does not account for its moisture dependency.

The results show that the effect of shallow groundwater on surface soil temperature is definite. However, to be detectable, this effect should be adequately large. We noticed that the temperature differences in the winter day were so small (about $\pm 0.5^{\circ} \mathrm{C}$ ), that it might be difficult to be detected remotely (Fig. 4). Contrarily, the differences in both summer days were large enough, and could be basically sensed using the currently operational thermal infrared sensors (Figs. 5 and 6).

Concerning the best time of the day to detect the shallow groundwater effect, the presented results show that all day and night hours are suitable when the effect of latent heat flux is predominant (Fig. 5). When the effect of volumetric heat capacity is predominant, most day and night hours are suitable except for the transition periods when the surface soil temperature of each profile equals one another (Figs. 4 and 6).

In our experiment, we applied two meters as water table depth; however the critical depth at which groundwater can still show its effect on land surface is different for each soil type. While the critical depth may be very small for groundwater in coarse well-drained soils as sands and gravels, it may reach up to several meters for groundwater in clayey soils.

To investigate how the behavior of different soil textures differs when shallow groundwater exists in the soil profile, we ran a set of additional simulations for three soil textures: sand, loam and clay (Table 1). Under the same setup (conditions) as in the previous experiment (weather forcing, profile depth and boundary conditions), SHAW simulations were run for each soil type. And for each soil type we ran seven simulations for seven profiles, one with no groundwater (NOGWP) while the rest with water table at 1, 2, 3, 4, 5 and $10 \mathrm{~m}$ depths (P1, P2, P3, P4, P5, P10) respectively. 


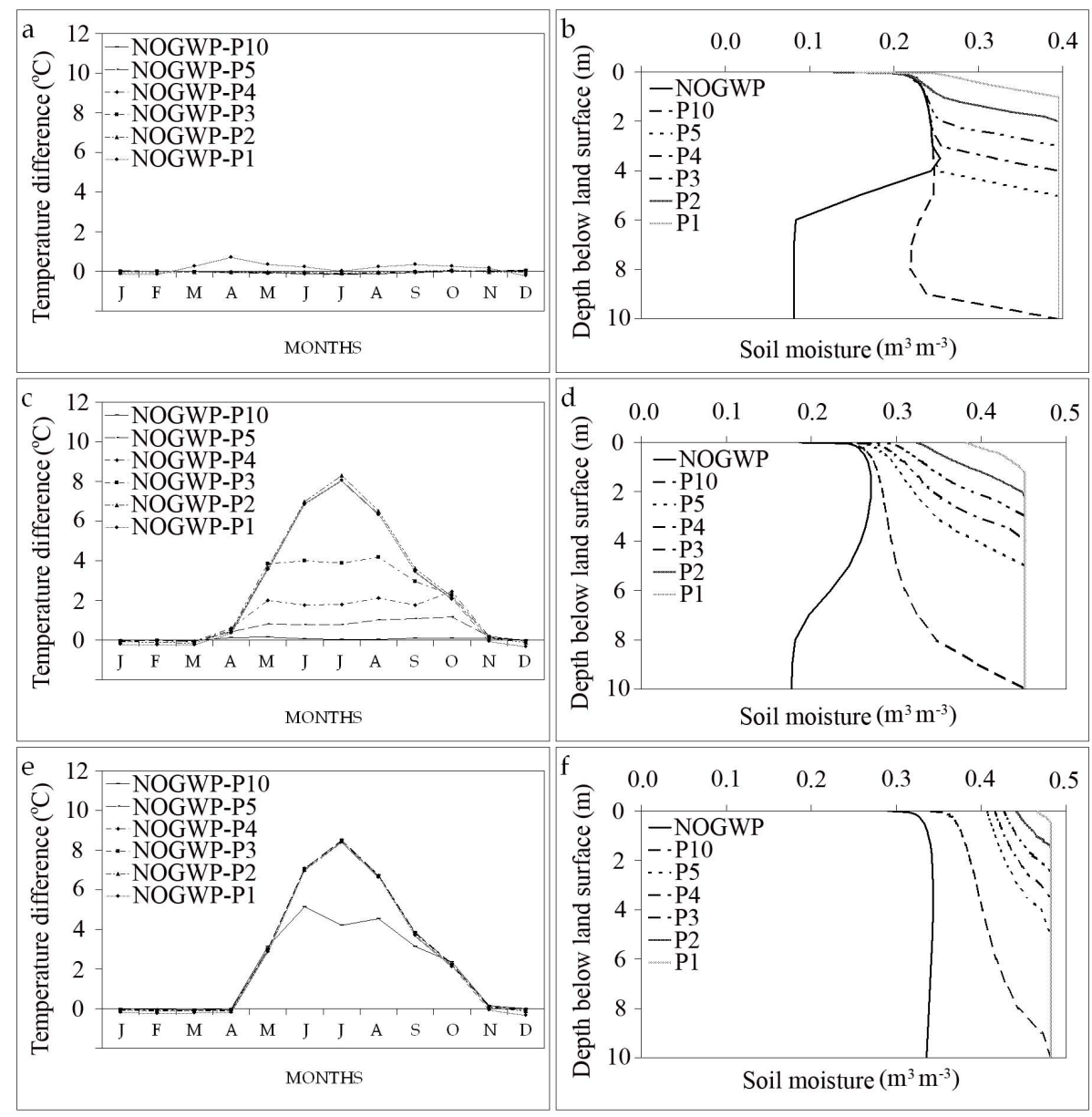

Fig. 7. The surface temperature differences between NOGWP and the profiles with water table at depths of 1, 2, 3, 4, 5 and 10 m of (a) sand, (c) loam and (e) clay. (b), (d) and (f): the annual average soil moisture profiles of the three soil types respectively.

The differences in the soil surface temperature between the NOGWP and those of other profiles were plotted in Fig. 7.

We noticed insignificant temperature differences among sandy profiles (Fig. 7a) which is characterized by high hydraulic conductivity and low capillary rise (Table 1). The only noticeable differences were for the profile of water table at $1 \mathrm{~m}$ depth. Where water table was below $1 \mathrm{~m}$ depth, the soil surface temperatures did not vary considerably among all other profiles.

For loamy soil (Fig. 7c), we found that the profiles have a clear contrast in surface temperature except for the two profiles with the shallowest water table (i.e. at 1 and $2 \mathrm{~m}$ ) and the two profiles with water table at $10 \mathrm{~m}$ and with no groundwater.

For clayey profiles (Fig. 7e), we noticed that the first five profiles with the shallow water table (i.e. at $1-5 \mathrm{~m}$ ) behave similarly. However the five profiles had different temperatures from the profile with water table at $10 \mathrm{~m}$ depth and the one with no groundwater.
To understand the behavior of the different soil types we may look at the yearly average soil moisture profiles for each of them. For sandy profiles (Fig. 7b), we noticed that except for the profile of water table at $1 \mathrm{~m}$ depth, the groundwater did not affect the moisture at land surface. This caused those profiles to have similar surface temperature. In this case, it is not possible to detect the groundwater depth below $1 \mathrm{~m}$ from surface temperature.

In the case of loamy profiles (Fig. 7d), the water table at one and two meters supplied the soil surface with enough moisture that the two profiles had similar soil temperature. The ability of water table to moisture the vadose zone decreased as the depth increased. Hence, the surface temperatures of profiles with water tables deeper than $2 \mathrm{~m}$ down to $5 \mathrm{~m}$ differentiated clearly. In this case it is easy to infer the water table depth from the surface temperature.

Finally, for clayey profiles (Fig. 7f), we noticed that water tables of $5 \mathrm{~m}$ depth and above increased the surface soil moisture above a value of $0.4 \mathrm{~m}^{3} \mathrm{~m}^{-3}$. This moisture supply was sufficient to satisfy the evaporation demand at the 
land surface. This made those profiles react similarly to the weather conditions and have similar surface temperatures.

The above analysis shows that the optimum conditions for shallow groundwater detection exist when the soil profile does not consist of only one of the extreme edges of soil types (sand or clay). In other words, the soil profile should range between these two extreme edges. Fortunately, the existence of soil profiles with pure soil textures (sand or clay) is not so common in nature. This enhances the chances of shallow groundwater depth detection in many regions via remote sensing. All in all, it is recommended to consider the composition of the soil layers in the area subject of study which will enhance the process of remote sensing when detecting groundwater effect.

In addition to the conclusions this analysis reaches, it also leads to future studies and discussions on the subsidiary effect of soil management as tillage practice on detecting shallow groundwater depth. The importance of such practice emanates from its effect on the soil porosity of the surface layer and consequently on its hydraulic properties. Compaction and tillage practice can reduce the porosity of the subsurface soil which can mess or destroy pore spaces creating a zone of low permeability at the bottom of the tilled layer. With the conclusions reached concerning the effect of soil types, it is advisable that further studies can be geared to evaluate the effect of soil management.

To maintain simplicity in this simulation study, three assumptions have been adopted: both heat and water transfers took place only in the vertical direction, the soil was homogeneous in both soil profiles, and the water table in GWP was stagnant during the simulation period. However, these conditions are not always present in the real world. And this may have further implications on the expected effect of shallow groundwater on soil temperature and the energy balance at land surface. While the vertical heat and water transfer may usually be predominant in the unsaturated zone, the soil profile can hardly be homogeneous. Accordingly, the vertical distribution of both thermal and hydraulic properties of the soil profile will be affected. Therefore, it is preferable to have information about the vertical distribution of soil layers in the area subject of study. This information is important to apply a more complete 3-D model of the phenomenon. This also applies for the third assumption regarding the stagnant water table. Thus, the suggested model should also consider the temporal fluctuations of water table in the study domain.

Finally it is worth mentioning that only bare soil conditions were considered in this study. When vegetation exists, other complexities arise. In such a case, the characteristics of the plant cover play a remarkable role in controlling the vertical water and heat transfer. Besides, different values of surface albedo and emissivity manifest. The magnitude of the plants effect depends on the type of the vegetation, its cover density and thickness, the root depth and density, etc. Further studies and investigations are recommended to predict the possibility of detecting the groundwater effect under this condition.

\section{Conclusions and recommendations}

The purpose of this investigation was to explore the features of shallow groundwater effect on land surface temperature and surface energy balance components under bare soil conditions. We illustrate that areas dominated by shallow groundwater have a wetter soil profile due to the upward water and vapor fluxes. Consequently, these areas responded differently to the prevailing atmospheric forcing. We highlight fundamental factors that take action within the scope of this effect.

Generally speaking, shallow groundwater areas reflect less shortwave radiation to the atmosphere due to their lower albedo and therefore, they absorb more shortwave radiation. When potential evaporation demand is adequately high, a large portion of the energy received by these areas is consumed for evaporation. This makes the latent heat flux predominant, and leaves less energy to warm the soil. When this condition occurs, lower magnitudes of both sensible and ground heat fluxes are induced.

The higher soil thermal conductivity in shallow groundwater areas facilitates heat transfer between the top soil and the subsurface which promotes greater provisional heat transfer in both vertical directions. That is to say, soil subsurface is more thermally connected to the atmosphere. Nevertheless, in all cases, deep soil temperatures eventually become even with surface and climate conditions; the deep temperatures become very close to the average annual temperature of the soil surface. Accordingly, the average annual soil heat flux for both profiles must be very close to zero in the long run.

With regards to remote sensors' capability of detecting the shallow groundwater effect on land surface temperature, we found that this effect can be sufficiently clear to be sensed if at least one of the following conditions are met: firstly, the latent heat flux effect is predominant due to the high potential evaporation, or secondly, soil volumetric heat capacity effect is strong due to the big contrast in air temperature between day and night.

Wherever it is possible to delineate the effect of shallow groundwater on a remotely sensed map of land surface temperature, it would be routinely feasible to highlight its effect on surface energy flux maps. These maps can be calculated by means of surface energy balance models, such as the Surface Energy Balance System (SEBS) (Su, 2002) which requires in addition to land surface temperature, remotely sensed data such as land surface albedo, emissivity, vegetation indexes, etc., jointly with other supplementary information collected in the field (weather conditions, soil data, etc.). The practical utilization of remote sensing data and SEBS in delineating shallow groundwater effect on land surface 
temperature and surface energy balance is illustrated in the companion paper (Alkhaier et al., 2012).

The numerical experiment in this study represents a special case; it was implemented for particular site, climate type, soil conditions and water table depth. In spite of that, it is helpful in highlighting the main aspects of shallow groundwater effect and in concluding important findings concerning shallow groundwater depth detection by means of thermal remote sensing. This is because we used (1) a soil type (loam) that consists of a relatively even mixture of sand, silt, and clay, and (2) a climate that has various weather conditions; wet and cold in winter, dry and hot in summer. However, the complex convoluted interactions among the different components of surface energy balance can differ from one region to another and from time to time in accordance with the site specific conditions. Hence, in areas where there is doubt concerning the chances and conditions of groundwater depth detection by means of thermal remote sensing, it is advisable to implement numerical simulations that consider the specific conditions prevailing in the area under investigation (i.e. site elevation and latitude, soil types and characteristics, climate type, water table depth, etc.).

Acknowledgements. The authors are grateful to the editor HarrieJan Hendricks Franssen, and to the three anonymous reviewers for their careful review and expert comments.

Edited by: H.-J. Hendricks Franssen

\section{References}

Alkhaier, F., Schotting, R. J., and Su, Z.: A qualitative description of shallow groundwater effect on surface temperature of bare soil, Hydrol. Earth Syst. Sci., 13, 1749-1756, doi:10.5194/hess-131749-2009, 2009.

Alkhaier, F., Su, Z., and Flerchinger, G. N.: Reconnoitering the effect of shallow groundwater on land surface temperature and surface energy balance using MODIS and SEBS, Hydrol. Earth Syst. Sci., 16, 1833-1844, doi:10.5194/hess-16-18332012, 2012.

Bense, V. F. and Kooi, H.: Temporal and spatial variations of shallow subsurface temperature as a record of lateral variations in groundwater flow, J. Geophys. Res., 109, B04103, doi:10.1029/2003JB002782, 2004.

Birman, H.: Geothermal exploration for groundwater, Geol. Soc. Am. Bull., 80, 617-630, 1969.

Brooks, R. H. and Corey, A. T.: Properties of porous media affecting fluid flow, J. Irrig. Drain. Div.-ASCE, 92, 61-88, 1966.

Brown, R. B.: Soil Texture, University of Florida, Institute of Food and Agricultural Sciences, fact sheet SL-29, 2003.

Campbell, G. S.: Simple method for determining unsaturated conductivity from moisture retention data, Soil Sci., 117, 311-314, 1974.

Campbell, G. S.: An Introduction to Environmental Biophysics, Springer-Verlag, New York, 1977.
Campbell, G. S.: Soil Physics with BASIC: Transport models for soil-plant systems, Elsevier, Amsterdam, 1985.

Cartwright, K.: Thermal prospecting for groundwater, Water Resour. Res., 4, 395-401, 1968.

Cartwright, K.: Redistribution of geothermal heat by a shallow aquifer, Geol. Soc. Am. Bull., 82, 3197-3200, 1971.

Cartwright, K.: Tracing shallow groundwater systems by soil temperatures, Water Resour. Res., 10, 847-855, 1974.

Chase, M. E.: Airborne remote sensing for groundwater studies in prairie environment, Can. J. Earth Sci., 6, 737-741, 1969.

Chen, X. and Hu, Q.: Groundwater influences on soil moisture and surface evaporation, J. Hydrol., 297, 285-300, 2004.

Clapp, R. B. and Hornberger, G. M.: Empirical equations for some soil hydraulic properties, Water Resour. Res., 14, 601-604, 1978.

de Vries, A. D.: Thermal properties of soils, in: Physics of plant environment, North Holland Publication Company, Amsterdam, The Netherlands, 210-235, 1963.

Dingman, S. L.: Physical Hydrology, Prentice-Hall Inc., Upper Saddle River, New Jersey, 2002.

Fan, Y., Miguez-Macho, G., Weaver, C. P., Walko, R., and Robock, A.: Incorporating water table dynamics in climate modeling: 1. Water table observations and equilibrium water table simulations, J. Geophys. Res., 112, D10125, doi:10.1029/2006JD008111, 2007.

Flerchinger, G. N.: The simultaneous heat and water (SHAW) model, Technical Report 37, Northwest Watershed Research Centre, USDA, Agricultural Research Service, Boise, Idaho, 2000.

Flerchinger, G. N. and Cooley, K. R.: A ten-year water balance of a mountainous semi-arid watershed, J. Hydrol., 237, 86-99, 2000.

Flerchinger, G. N. and Hardegree, S. P.: Modelling near-surface soil temperature and moisture for germination response predictions of post-wildfire seedbeds, J. Arid Environ., 59, 369-385, doi:10.1016/j.jaridenv.2004.01.016, 2004.

Flerchinger, G. N., Sauer, T. J., and Aiken, R. A.: Effects of crop residue cover and architecture on heat and water transfer at the soil surface, Geoderma, 116, 217-233, doi:10.1016/S00167061(03)00102-2, 2003.

Flerchinger, G. N., Xiao, W., Sauer, T. J., and Yu, Q.: Simulation of within-canopy radiation exchange, NJAS-Wagen. J. Life Sc., 57, 5-15, 2009.

Furuya, G., Suemine, A., Sassa, K., Komatsubara, T., Watanabe, N., and Marui, H.: Relationship between groundwater flow estimated by soil temperature and slope failures caused by heavy rainfall, Shikoku Island, south western Japan, Eng. Geol., 85, 332-346, doi:10.1016/j.enggeo.2006.03.002, 2006.

Grismer, M. E., Orang, M. N., Clausnitzer, V., and Kinney, K.: Effects of air compression and counterflow on infiltration into soils, J. Irrig. Drain. E.-ASCE, 120, 775-795, doi:10.1061/(ASCE)0733-9437(1994)120:4(775), 1994.

Gulden, L. E., Rosero, E., Yang, Z., Rodell, M., Jackson, C. S., Niu, G., Yeh, P. J.-F., and Famiglietti, J.: Improving landsurface model hydrology: Is an explicit aquifer model better than a deeper soil profile?, Geophys. Res. Lett., 34, L09402, doi:10.1029/2007GL029804, 2007.

Heilman, J. L. and Moore, D. G.: Evaluating depth to shallow groundwater using heat capacity mapping mission (HCMM) data, Photogramm. Eng. Rem. S., 48, 1903-1906, 1982. 
Huang, M. and Gallichand, J.: Use of the SHAW model to assess soil water recovery after apple trees in the gully region of the Loess Plateau, China, Agr. Water Manage., 85, 67-76, doi:10.1016/j.agwat.2006.03.009, 2006.

Hulley, G. C., Hook, S. J., and Baldridge, A. M.: Investigating the effects of soil moisture on thermal infrared land surface temperature and emissivity using satellite retrievals and laboratory measurements, Remote Sens. Environ., 114, 1480-1493, 2010.

Huntley, D.: On the detection of shallow aquifers using thermal infrared imagery, Water Resour. Res., 14, 1075-1083, 1978.

Idso, S. B., Jackson, R. D., Reginato, R. J., Kimball, B. A., and Nakayama, F. S.: The dependence of bare soil albedo on soil water content, J. Appl. Meteorol., 14, 109-113, 1975.

Jiang, X. Y., Niu, G. Y., and Yang, Z. L.: Impacts of vegetation and groundwater dynamics on warm season precipitation over the central United States, J. Geophys. Res., 114, D06109, doi:10.1029/2008JD010756, 2009.

Johnson, G. L., Hanson, C. L., Hardegree, S. P., and Ballard, E. B.: Stochastic weather simulation: Overview and analysis of two commonly used models, J. Appl. Meteorol., 35, 1878-1896, 1996.

Johnson, G. L., Daly, C., Taylor, G. H., and Hanson, C. L.: Spatial variability and interpolation of stochastic weather simulation model parameters, J. Appl. Meteorol., 39, 778-796, 2000.

Kappelmeyer, O.: The use of near surface temperature measurements for discovering anomalies due to causes at depths, Geophys. Prospect., 5, 239-258, 1957.

Kottek, M., Grieser, J., Beck, C., Rudolf, B., and Rubel, F.: World Map of the Köppen-Geiger climate classification updated, Meteorol. Z., 15, 259-263, doi:10.1127/0941-2948/2006/0130, 2006.

Krcmar, B. and Masin, J.: Prospecting by the geothermic method, Geophys. Prospect., 18, 255-260, doi:10.1111/j.13652478.1970.tb02106.x, 1970.

Liang, X. and Xie, Z.: Important factors in land-atmosphere interactions: surface runoff generations and interactions between surface and groundwater, Global Planet. Change, 38, 101-114, 2003.

Maxwell, R. M. and Miller, N. L.: Development of a coupled land surface and groundwater model, J. Hydrometorol., 6, 233-247, 2005.

Mira, M., Valor, E., Boluda, R., Caselles, V., and Coll, C.: Influence of soil water content on the thermal infrared emissivity of bare soils: Implication for land surface temperature determination, J. Geophys. Res., 112, F04003, doi:10.1029/2007JF000749, 2007.
Niu, G.-Y., Yang, Z.-L., Dickinson, R. E., Gulden, L. E., and $\mathrm{Su}, \mathrm{H}$.: Development of a simple groundwater model for use in climate models and evaluation with Gravity Recovery and Climate Experiment data, J. Geophys. Res., 112, D07103, doi:10.1029/2006JD007522, 2007.

Olmsted, F. H., Welch, A. H., and Ingebritsen, S. E.: Shallow subsurface temperature surveys in the basin and range province, U.S.A. I. Review and evaluation, Geothermics, 15, 251-265, 1986.

Peel, M. C., Finlayson, B. L., and McMahon, T. A.: Updated world map of the Köppen-Geiger climate classification, Hydrol. Earth Syst. Sci., 11, 1633-1644, doi:10.5194/hess-11-16332007, 2007.

Quiel, F.: Thermal/IR in geology, Photogramm. Eng. Rem. S., 41, 341-346, 1975.

Salisbury, J. W. and Daria, D. M.: Infrared $(8-14 \mu \mathrm{M})$ remotesensing of soil particle-size, Remote Sens. Environ., 42, 157$165,1992$.

Salvucci, G. D. and Entekhabi, D.: Ponded infiltration into soils bounded by a water table, Water Resour. Res., 31, 2751-2759, 1995.

Santanello, J. A. and Friedl, M. A.: Diurnal covariation in soil heat flux and net radiation, J. Appl. Meteorol., 42, 851-862, 2003.

Su, Z.: The Surface Energy Balance System (SEBS) for estimation of turbulent heat fluxes, Hydrol. Earth Syst. Sci., 6, 85-100, doi:10.5194/hess-6-85-2002, 2002.

Takeuchi, A.: Method of investigating groundwater-vein-streams by measuring one-meter-depth in landslide areas (I), J. Japan. Assoc. Groundw. Hydrol., 22, 11-39, 1980.

Takeuchi, A.: Method of investigating groundwater-vein-streams by measuring one-meter-depth in landslide areas (II), J. Japan. Assoc. Groundw. Hydrol., 23, 1-27, 1981.

Takeuchi, A.: Investigation methods of flowing groundwater by temperature measurements, Kokon Shoin, 367-468, 1996.

van den Bouwhuysen, J. N. A.: The thermocouple proves useful on a geophysical survey, Eng. Min. J., 135, 342-344, 1934.

York, J. P., Person, M., Gutowski, W. J., and Winter, T. C.: Putting aquifers into atmospheric simulation models: an example from the Mill Creek watershed, northeastern Kansas, Adv. Water Resour., 25, 221-238, 2002.

Yuhara, K.: Isothermal layer, Groundwater handbook, revised version, Editorial committee of Groundwater handbook, Kensetsu Sangyo Chosakai, 120-121, 1998. 